\title{
Wind Power Influence on the Small Signal Stability of Grid Integrated Distribution Systems
}

\author{
Ramprasad Vangalapudi ${ }^{1}$, Dr. K.Ravikanth ${ }^{2}$ \\ ${ }^{1}$ Research Scholar, University of Technology, Jaipur, Rajasthan, India, ramprasadgurukul@ gmail.com \\ ${ }^{2}$ Professor, University of Technology, Jaipur, Rajasthan, India, drravikanthuot@ gmail.com
}

\begin{abstract}
Use of wind power generation is increasing nowadays, particularly in the broader sense of the distribution areas. The technological impacts and constraints are still under study, and are almost unchanged in many ways. One consequence of this is the low-signal reliability of delivery networks. This paper analyzes the influence of wind power on a Grid Integrated distribution system's small signal stability. Factors such as level of integration of wind power, wind turbine technology, device activity, location of the wind farms and distributed wind farms are considered. Using modal analysis, the oscillatory modes which arise due to changes in system operating conditions are computed. The behavior of synchronous generators is corroborated with the aid of analysis of the time domain. The findings showed that the integration of wind turbines increases the damping ratio and reduces the oscillatory frequency of all modes. The point of interconnection and the generation of distributed winds have no effect on damping ratio and oscillatory frequency.
\end{abstract}

Key words : Grid Integrated distribution system; modal analysis; small signal stability; wind power

\section{INTRODUCTION}

The incorporation of wind power into power systems has increased over the last decade. This reality leads to increasing concern about its effect on a power system's operation and stability [1-2]. Much of these concerns focus on the impact of integration of wind power on voltage [3-4] and frequency stability [5-6], with less attention being paid to the small stability of the signals. The increasing penetration of induction machines as wind generators raises concerns regarding rotor oscillations and increased stability of induction generators as well as distribution system.

The effect on the ratio of oscillatory frequency and damping depends on the model used for generator. In the case of an induction generator for squirrel cage (SCIG), it is known to have a beneficial effect on the damping of electromechanical oscillations [7]. However, applications are not generalized for double-fed induction generator (DFIG); damping is reduced in some studies [8] and damping is increased in others [9]. It presents a comparison of both technologies in [10]. The tests indicate the best DFIG behaviour. However, the effect on the stability of small signals depends not only on the wind turbine technology but also on the frequency of oscillation and damping ratio, the system, its design, the form of generation and its control system.

Different methods reported for analyzing a power system's small signal stability include probabilistic methods [11], small signals stabilization area boundaries [12], time domain simulations [7], and modal analysis by measurement of its own value [8]. The limited study of the signal stability with the application of wind power was applied to different power systems. For example: 68 bus test system [13], IEEE New England system [14], Uruguayan system [8], and a distribution system interconnected to the transmission system [7] have been recorded in IEEE 16 generators. The scope of this paper is to identify the influence of wind power on the small signal stability of the Grid Integrated distribution system, taking into account factors such as the level of integration of wind power, the interconnection point with the electrical grid and the dispersed wind production.

\section{MATERIALS AND METHODS}

\subsection{System Modelling}

Typically, elements which should be considered for various stability studies in modeling a power system are generators, generator controllers, transformers, transmission lines and loads. The modeling approach employed in this paper is described below.

\subsection{Synchronous Generator}

Synchronous generators are described by sixth-order model in the transient stability analysis [15]. Usually synchronous generators are connected as constant active power sources running in the mode of control of the power factor to distribution systems. However, they can support the voltage 
by also providing the reactive power, depending on their capability. Reactive power limit has been established for voltage control mode. The diesel generators act as base power which provides voltage control in the system under review.

\subsection{Wind Turbine Model}

Wind generators available today are classified into four main types of turbines:

- Type 1: Fixed speed wind turbine with induction generator connected to direct grid.

- Type 2: Variable speed wind turbine directly connected to the grid, with variable rotor resistance induction generator.

- Type 3: Variable speed wind turbine with dual fed induction generator and $\mathrm{dc} / \mathrm{ac}$ rotor converter connected to direct grid.

- Type 4: Wind turbine with variable speed with synchronous machine and full scale ac / dc / ac converter.

Type 3 wind turbine was the selected technology because it is the technology present under study in the power system. The Double Feed Induction Generator (DFIG) configuration corresponds to a small variable speed wind turbine with a wound rotor induction generator and a partial frequency converter on the rotor circuit (rated at approximately 30 percent of the nominal power generator). The reactive power compensation and the smoothest grid connection is carried out by the partial scale frequency converter. You will find the mathematical model here in [16].

\subsection{Wind Model}

Wind has been modeled as a Weibull distribution; wish is described as: equation (1).

$$
f\left(v_{w}, c, k\right)=\frac{k}{c^{k}} v_{w}^{k-1} e^{-\left(\frac{v_{w}}{c}\right)^{k}}
$$

Where VW is the wind speed, $\mathrm{k}$ is shape factor and $\mathrm{c}$ is scale factor.

Time variations VW ( $t$ ) of the wind speed are then obtained by means of a Weibull distribution, as follows: equation (2).

$$
v_{W}(t)=\left(-\frac{\ln t(t)}{c}\right)^{\frac{1}{k}}
$$

Where $\mathrm{l}(t)$ is a generator of random numbers between 0 and 1. The output power of wind turbine depends on wind speed and the approximate relationship between them is: equation (3).

$$
P= \begin{cases}0 & V \leq V_{c i}, V \geq V_{c o} \\ P_{r d} \frac{V-v_{c i}}{V_{r}-v_{c i}} & v_{c i} \leq V \leq V_{r} \\ P_{r d} & v_{r} \leq V \leq V_{c o}\end{cases}
$$

Where V is wind speed on fan hub, Vci is cut-in wind speed, Vco is cut-out wind speed, Vr is rated wind speed and Prd is rated power of wind turbine.

\subsection{Small Signal Stability}

Small signal stability is the control system's ability to preserve synchronization when subjected to minor disturbances [15]. In this context, a disturbance is considered to be small if it is possible to linearize the equations which describe the resulting system response. The system used for the analysis of small signal stability is a set of algebraic differential equations, in the form of: equation (4).

$$
\begin{aligned}
& \dot{x}=f(x, u) \\
& 0=g(x, u)
\end{aligned}
$$

Where: equation (5).

$$
\begin{aligned}
& x=\left(x_{1}, x_{2}, \ldots \ldots \ldots, x_{n}\right)^{T} \\
& u=\left(u_{1}, u_{2}, \ldots \ldots \ldots, u_{n}\right)^{T} \\
& g=\left(g_{1}, g_{2}, \ldots \ldots g_{n}\right)^{T}
\end{aligned}
$$

Where $x$ is the vector of the state variables, $u$ is the input vector and $g$ is a vector of nonlinear functions relating state and input variables to output variables. The analysis is based on the nonlinear set of system equations, dynamic relations as well as network equations, which are linearized in an operating point to obtain a linear system. Therefore, the nonlinear equations are linearized using Taylor series. The linear result equation is written as (6):

$$
\begin{aligned}
& \Delta \dot{x}=A \Delta x+B \Delta u \\
& 0=C \Delta x+D \Delta u
\end{aligned}
$$

Where $\mathrm{A}$ is the system state matrix, $\mathrm{B}$ the input matrix, $\mathrm{C}$ the output matrix and D the feed forward matrix. Taking the Laplace transformation of equations (6), will result in: equation (7).

$$
\begin{aligned}
& \Delta \dot{x}(s)=\frac{\operatorname{adj}(s I-A)}{\operatorname{det}(s I-A)} B \Delta u(s) \\
& \Delta y(s)=C \frac{\operatorname{adj}(s I-A)}{\operatorname{det}(s I-A)} B \Delta u(s)+D \Delta u(s)
\end{aligned}
$$

The poles of $\Delta x(s)$ and $\Delta y(s)$ are the roots of the equation (8): $\operatorname{det}(s I-A)=0$

Equation (8), can be re written as equation (9):

$$
\operatorname{det}(A-\lambda I)=0
$$

Expansion of the determinant gives the characteristic equation. The $n$ solutions of $\lambda$ are the eigenvalues of matrix A. It contains information about the response of the system to a small perturbation. The eigenvalue may be real or complex. The complex values always appear in conjugate pairs if $\mathrm{A}$ is real. The real component of the eigenvalues gives the damping, and the imaginary component gives the frequency of oscillation. Thus, for a complex pair of eigenvalues: equation (10). 
Ramprasad Vangalapudi et al., International Journal of Emerging Trends in Engineering Research, 8(7), July 2020, 3569 - 3574

$$
\lambda_{i}=\sigma_{i} \pm j \omega_{i}
$$

Where the frequency of oscillation in $\mathrm{Hz}$, and the damping ratio are given by equation (11) and (12).

$$
\zeta=\frac{-\sigma_{i}}{\sqrt{\sigma_{i}^{2}+\omega_{i}^{2}}}
$$

Each eigenvalue represents a system mode and the relationship between this mode and the stability is given by Lyapunov [15], where the system is stable when $\sigma_{\mathrm{i}}<0$; the system is unstable when $\sigma_{\mathrm{i}}>0$; and in general, no conclusions arise when

$$
\sigma_{i}=0
$$

\section{SYSTEM UNDER STUDY}

The system being studied is an integrated radial distribution network with a max. load of 17.7 MW and 6.2 Mvar. This charge is supplied only by distributed generation technology. The loads are supplied by four 4.5 MVA MAN diesel generators connected to bus 2 and 3 and four 2,36 MVA MTU diesel generators distributed throughout the network. Improving quality service and supporting the MAN generators at full load condition are the key functions of MTU generators. The delivery network has a voltage standard of $34.5 \mathrm{kV}$ and 7 substations. A base case is device without incorporation of wind power. Eigenvalues of the base case are determined and 68 own values are derived with the negative real component value. Figure 1 shows some of the most important values.

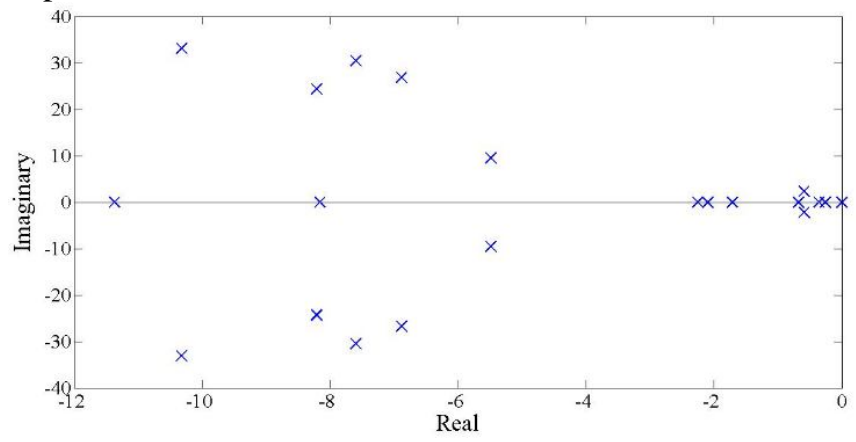

Figure 1: Eigenvalues for the base case scenario

The scheme is asymptotically stable, as all own values are on the left side of the imaginary axis. Nine of the individual values are complex and denote an oscillatory mode. Table 1 displays only results from the oscillatory mode. It is important to note that the oscillatory frequencies of seven of the nine modes are between 4 and $6 \mathrm{~Hz}$, which is greater than the frequency of broad generator electromechanical modes found in transmission systems, standard values between 0,1 and 2 $\mathrm{Hz}[16]$.

Some studies also indicate a frequency of oscillations about 3 $\mathrm{Hz}$ in control systems [7]. Such systems are therefore linked by a strong link to a transmission network. Another example is the Uruguayan power system [8] with certain modes oscillating in frequency about $3 \mathrm{~Hz}$. The findings of the oscillatory frequencies are rational when comparing these with the system under review and considering that the diesel generators are close between them.

Table 1: Electromechanical mode of the study system

\begin{tabular}{|l|l|c|c}
\hline \multicolumn{1}{|c|}{ Modes } & \multicolumn{1}{c|}{$\boldsymbol{\sigma} \pm \mathbf{j} \boldsymbol{\omega}$} & Frequency $(\mathbf{H z})$ & Damping Ratio \\
\hline Mode 5,6 & $-10,319 \pm 33,0976$ & 5,518 & 0,298 \\
\hline Mode 7,8 & $-11,8387 \pm 34,1594$ & 5,754 & 0,327 \\
\hline Mode 9,10 & $-7,5949 \pm 30,5123$ & 5,004 & 0,242 \\
\hline Mode 11, 12 & $-6,8791 \pm 26,7876$ & 4,402 & 0,249 \\
\hline Mode 14, 15 & $-8,2088 \pm 24,3146$ & 4,084 & 0,320 \\
\hline Mode 16,17 & $-8,2077 \pm 24,3217$ & 4,086 & 0,320 \\
\hline Mode 19,20 & $-8,2067 \pm 24,3288$ & 4,086 & 0,320 \\
\hline Mode 25,26 & $-5,4895 \pm 9,5765$ & 1,757 & 0,497 \\
\hline Mode 39,40 & $-0,5952 \pm 2,2881$ & 0,376 & 0,252 \\
\hline
\end{tabular}

According to [8] the damping ratio is considered low for values less than 0.05 . These values are above all the damping expressed in Table 1. So, the Grid Integrated distribution system under research can be said to have a strong damping effect.

Two local modes and the interarea mode between area one and area two can be analyzed because of the number of generators and their distribution within the network. According to the participation factors study, a local mode of area one is represented by the MAN generators, the main contribution of these generators is in modes 9 and 10. The region two is defined by MTU generators, and the modes 5 and 6 are the most appropriate mode with less damping ratio. Finally, in Modes 14 and 15 the inter-area mode is represented. Analysis of the time domain was conducted to imagine synchronous generator rotor oscillations for baseline case scenario. In the second 10 of the simulation, a three-phase short-circuit fault was applied to bus 8 and cleared after $70 \mathrm{~ms}$. MAN and MTU synchronous generators rotor speeds were observed in Figure 2.

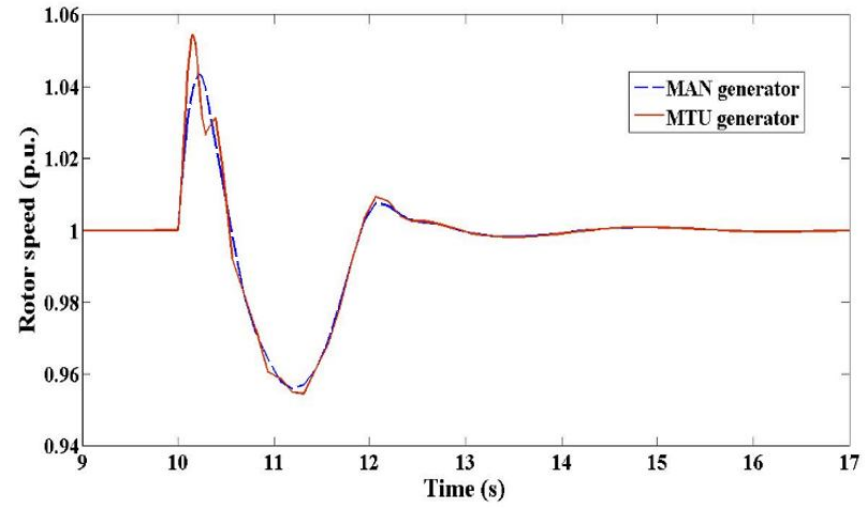

Figure 2: Response of MAN and MTU synchronous generator

The behavior is very similar for both of the synchronous generator technologies. The oscillation frequency is about $0.35 \mathrm{~Hz}$, which corresponds to the modes 39 and 40 shown in table 1. Such modes are the dominants in this case, which refer to the MAN generator excitation system. In order to test 
this activity a connection is made in the program under review with a real-life occurrence occurring. Figure 3, demonstrates the device frequency response to a perturbation. The real oscillation frequency in the device is about $0.34 \mathrm{~Hz}$, which is also the range shown by the study of own values. The difference with the simulation is less than 3 percent, so the system behavior and models are validated and the system is ready with wind turbines to analyze small signals.

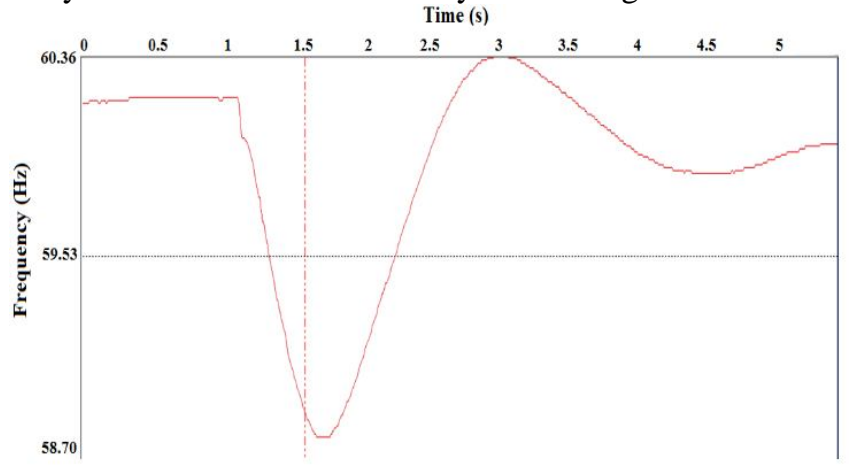

Figure 3: Real frequency response

\section{SIMULATION RESULTS AND DISCUSSIONS}

The global concern about environmental concerns and regulatory changes is to promote the use of more renewable energy resources that are likely to be incorporated into the distribution network in the future. The following topics are studied for the examination of the effects of wind farm incorporation into the program under study:

1. Influence of wind power increase on the oscillatory modes without disconnecting diesel generators.

2. Influence of wind power increase on the oscillatory modes disconnecting diesel generators.

3. Influence of interconnection point of wind turbines.

4. Influence of dispersed wind farm on the oscillatory modes.

5. Time domain simulation.

The wind farm (WF) is assumed to be connected to the system via a line with a resistance of $0.292 \mathrm{pu}$ and a reaction of 0.267 $\mathrm{pu}$, with the same bases as Appendix A. The wind farm consisting of DFIG type wind turbines with a total capacity of $2 \mathrm{MW}$ is connected to the grid. At unity power factor the power is injected into the grid. This is achieved through the pulse between the generator rotor and the grid with modulation frequency converter. This technology's used model is described at[17].

\subsection{Influence of Wind Power Increase on the Oscillatory Modes without Diesel Generators Disconnected}

A wind farm consisting of the DFIG connects to bus 19. The starting power of wind farms was $2 \mathrm{MW}$, and the same is increased to $2 \mathrm{MW}$ while the MTU generators' output power is reduced to its limits, and then the power output of MAN generators was decreased by the same amount so that the total power remained the same. The damping of the oscillatory modes selected for the study is shown in figure 4 , and the oscillatory frequency is shown in table 2. Under these conditions the average wind power which could be incorporated was $6 \mathrm{MW}$.

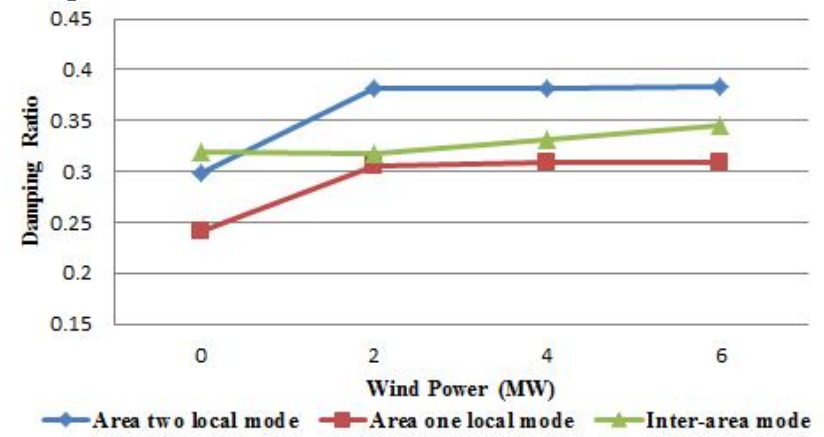

Figure 4: Influence of wind power increase using DFIG on the damping of electromechanical mode

Table 2: Oscillatory frequency for increase wind power

\begin{tabular}{|c|c|c|c|}
\hline Wind farm & Area One & Area Two & Inter-area \\
\hline Base Case & 5,004 & 5,518 & 4,084 \\
\hline 2MW & 4,826 & 5,354 & 4,095 \\
\hline $4 \mathrm{MW}$ & 4,846 & 5,359 & 4,072 \\
\hline $6 \mathrm{MW}$ & 4,853 & 5,356 & 4,062 \\
\hline
\end{tabular}

The results show that damping of the inter-area frequency mode increases marginally when the wind farm capacity is up to $6 \mathrm{MW}$ thus positively influencing the local modes. The rise in area one damping ratio was 29 percent and 28 percent for area two. For DFIG wind farm, the oscillatory frequency in area one and two decreased by up to $6 \mathrm{MW}$, while in inter-area mode it decreased slightly.

\subsection{Influence of Wind Power Increase on the Oscillatory Modes with Diesel Generators Disconnected}

The traditional systems will usually be replaced by wind power. Throughout this segment, increasing wind power means shutting down a diesel generator, beginning with MTU technology, with the exception of the MTU generator at bus 12 , while maintaining the voltage between limits nearby. When three of the four MTUs are disconnected and the wind power is that continuously, a MAN generator must be disconnected. As DFIG wind turbine joins the area damping ratio, one local mode is nearly constant at about 0.25 until a 6 MW wind farm; for $8 \mathrm{MW}$ the damping ratio increases to 0.34 . At this stage the machine operates at bus 12 with both MAN generators and the MTU generator. If a wind farm 's installed power is up to $10 \mathrm{MW}$, one MAN generator is disconnected at bus 3 . At this stage, the wind farm replaces an excitation device with a synchronous unit. The damping in area one is therefore affected, and has a reduction of 0.3. Integrating DFIG wind turbine up to $10 \mathrm{MW}$ increases damping ratio and lowers the device under study's oscillatory frequency. Under this condition, as shown in Figure 5, the device is stable for small signal, with a real negative portion for all proper values. 


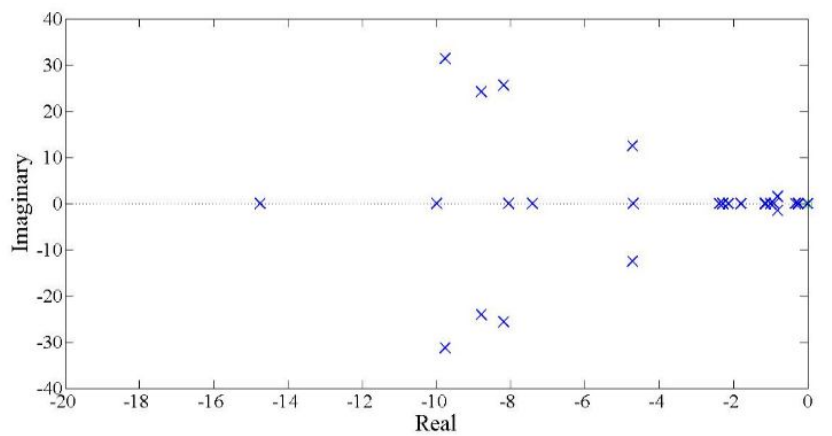

Figure 5: Eigenvalues for $10 \mathrm{MW}$ with a DFIG wind farm.

The damping of area two is the same when the wind farm is up to $10 \mathrm{MW}$, states that in area two the wind farm interconnects to the system; in some way the incorporation of the wind farm in this area eliminates the damping loss for the disconnection of the diesel generators. The inter-area damping increases marginally to 0.34 .

A reduction in the oscillation frequency in area one is observed from 5 to $4.28 \mathrm{~Hz}$ ( 15 percent reduction). In area two, the oscillatory frequency reduction was 5 percent, while the inter-area mode frequency for all wind farm integration values is mostly the same.

\subsection{Influence of the Interconnection Point of Wind Turbines}

The 4 MW wind farm was linked to various buses to test the effect of shift in wind generator positions on the low signal stability of a power system. In these cases, the power system does not remove any diesel generators. The results are set out in Table 3.

Table 3: Damping and oscillatory frequency for a 4 MW DFIG wind

\begin{tabular}{|c|c|c|c|c|c|c|}
\multicolumn{9}{|c|}{ farm } \\
\hline \multirow{2}{*}{ farm location } & \multicolumn{2}{|c|}{ Area One } & \multicolumn{2}{c|}{ Area Two } & \multicolumn{2}{c|}{ Inter-area } \\
\cline { 2 - 7 } & Damping & Freq.(Hz) & Damping & Freq.(Hz) & Damping & Freq.(Hz) \\
\hline Bus 10 & 0,307 & 4,828 & 0,381 & 5,360 & 0,333 & 4,067 \\
\hline Bus 14 & 0,307 & 4,827 & 0,382 & 5,355 & 0,332 & 4,070 \\
\hline Bus 19 & 0,309 & 4,846 & 0,382 & 5,359 & 0,332 & 4,072 \\
\hline Bus 26 & 0,308 & 4,824 & 0,383 & 5,352 & 0,331 & 4,075 \\
\hline Bus 28 & 0,307 & 4,825 & 0,383 & 5,352 & 0,332 & 4,074 \\
\hline Bus 33 & 0,315 & 4,912 & 0,383 & 5,345 & 0,330 & 4,090 \\
\hline Bus 36 & 0,307 & 4,830 & 0,381 & 5,357 & 0,333 & 4,064 \\
\hline
\end{tabular}

The interconnection point does not affect the damping ratio and the oscillatory frequency for a $4 \mathrm{MW}$ wind farm with DFIG technology. All parameters, at any wind spot, are almost the same for all area modes.

\subsection{Influence on the Oscillatory Modes of Dispersed Wind Farm}

Normally the interconnection of renewable energy resources in the delivery system is distributed into many grid points. The influence of dispersed wind farm in damping ratio is analyzed, and the oscillatory frequency of each mode. The distinction was made between a focused $6 \mathrm{MW}$ wind farm on bus 19, and six 1MW wind farms on bus 10, 14, 19, 26, 28 and 33. The findings are shown in Table 4.
Table 4: Frequency and damping ratio for a DFIG wind farm

\begin{tabular}{|c|c|c|c|}
\hline \multirow{2}{*}{ Wind farm } & \multicolumn{3}{|c|}{ Damping ratio } \\
\cline { 2 - 4 } & Area One & Area Two & Inter-area \\
\hline Concentrated & 0,309 & 0,383 & 0,346 \\
\hline Dispersed & 0,308 & 0,379 & 0,349 \\
\hline & \multicolumn{3}{|c|}{ Oscillatory frequency } \\
\hline & Area One & Area Two & Inter-area \\
\hline Concentrated & 4,853 & 5,356 & 4,062 \\
\hline Dispersed & 4,845 & 5,359 & 4,038 \\
\hline
\end{tabular}

For local and inter-area modes, the damping ratio and the oscillatory frequency are very close in every case.

\subsection{Time Domain Simulation}

To test the behavior of synchronous generators with wind energy integration a simulation of the time domain is performed. The study was made for the most important condition; refer to the second scenario, that is to say, the situation when the diesel generators were disconnected in the case of integration of wind turbines. In this case, the wind farm is $10 \mathrm{MW}$ and, in all cases, studied, it represents the bigger wind penetration. A three-phase short-circuit fault was applied on bus 8 for the study and cleared after $70 \mathrm{~ms}$. MAN generator rotor speeds were observed in figure 6 .

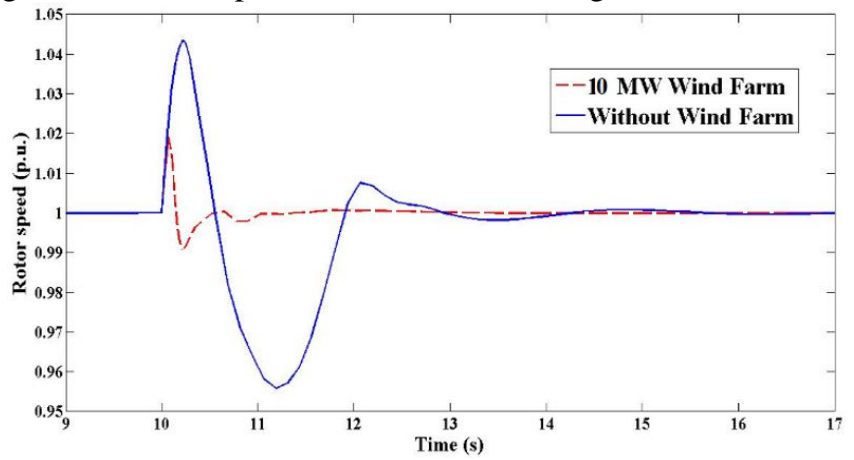

Figure 6: Response of MAN generator with a without wind energy integration

Connecting a $10 \mathrm{MW}$ wind farm improves the response of the MAN generator, the speed of the rotor has a better behavior with less peak, less oscillation and a better oscillation frequency.

\section{CONCLUSION}

A distribution network with DFIG wind farm integration was investigated for the small signal stability. The frequency oscillation modes were observed with approximately $5 \mathrm{~Hz}$ for base case. In both local and inter-area modes, the system has a good damping ratio and is robust for small signals. Integration of wind farms improves the damping ratio and reduces area one, area two and inter-area mode oscillatory frequencies. Owing to the introduction of wind power a disparity is found when diesel generators are disconnected. 10 MW can be integrated for a wind farm at DFIG. As compared with the base case, an increase in the damping ratio and a decrease in oscillatory frequency was observed. The wind farm's interconnecting point with the network and the alignment of the scattered wind farm has no major effect in the damping ratio and the oscillatory frequency of local and inter-area modes. 


\section{REFERENCES}

1. NIKMEHR, N. and Najafi-Ravadanegh, S. "Optimal operation of distributed generations in micro-grids under uncertainties in load and renewable power generation using heuristic algorithm'. Renewable Power generation, IET, 2015, vol. 9, n8, p. 982-990.ISSN: 1752-1424.

DOI: $10.1049 /$ iet-rpg.2014.0357

2. SHI, L., Sun, S., Yao, L., Ni, Y. and Bazargan, M. "Effects of wind generation intermittency and volatility on power system transient stability". Renewable Power generation, IET, 2014. v. 8, n.5, p. 509-521.ISSN. 1752-1424.

DOI: 10.1049/iet-rpg.2013.0028.

3. MEEGAHAPOLA, L. and Littler, T. "Characterization of large disturbance rotor angle and voltage stability in interconnected power networks with distributed wind generation". Renewable Power generation, IET, 2015. v. 9, n.3, p. 272-283, ISSN. 1752-1424.

DOI: $10.1049 /$ iet-rpg.2013.0406

4. KASSEM, A. M. and Abdelaziz, A. Y. "Reactive power control for voltage stability of standalone hybrid wind-diesel power system based on functional model predictive control". Renewable Power generation, IET, 2014. v. 8, n. 8, p. 887-899.ISSN. 1752-1424.

DOI: $10.1049 /$ iet-rpg.2013.0199

5. WANG, Y., Silva, V. and Lopez-Botet-Zulueta, M. "Impact of high penetration of variable renewable generation on frequency dynamics in the continental Europe interconnected system". Renewable Power generation, IET, 2016. v. 10, n. 1, p. 10-16, ISSN. 1752-1424.DOI: $10.1049 /$ iet-rpg.2015.0141

6. WU, L. and Infield, D. "Power system frequency management challenges - a new approach to assessing the potential of wind capacity to aid system frequency stability". Renewable Power generation, IET, 2014. vol. 8, n 7, p. 733- 739, ISSN. 1752-1424. DOI: $10.1049 /$ iet-rpg.2013.0424

7. DAHAL, S., Mithulananthan N. and Saha, T. "Investigation of small signal stability of a renewable energy based electricity distribution system". In Proc. Power and Energy Society General Meeting, Providence, USA, July, 2010. p. 1-8. ISSN. 1944-9925. DOI: $10.1109 /$ PES.2010.5590113

8. BERRUTTI, F., Giusto, A. and Artenstein, M. "Modal analysis of the Uruguayan power system incorporating largescale wind generation"'. In Proc. T\&D LAIEEE/PES, Montevideo, Uruguay, September, 2012. p.1-6, ISBN. 978-1- 4673-2673-5.

DOI: 10.1109/TDC-LA.2012.6319075

9. SUN, B., He, Z., Jia, Y. and Liao, K. "Small-Signal Stability Analysis of Wind Power System Based on DFIG". Energy and Power Engineering, IEEE, 2013, vol. 5, p. 418-422, DOI: 10.4236/epe.2013.54B081

10. AL-MASARI, O. and AL-Masari, M. "Enhancement of Small Signal Stability of Wind Farms by Using
STATCOM and HVDC Link". International Journal of Emerging Science and Engineering, 2015.vol. 3, n. 4, ISSN. 2319-6378.

11. BU, S. Q., et al., "Probabilistic Analysis of Small-Signal Stability of Large-Scale Power Systems as Affected by Penetration of Wind Generation". Transactions on Power Systems, IEEE, 2012. vol. 27, n 2, p. 762-770, ISSN. 1558- 0679.

DOI: 10.1109/TPWRS.2011.2170183

12. LIU, W., Ge, R., Liand, H. and Ge, J. "Impact of Large-Scale Wind Power Integration on Small Signal Stability Based on Stability Region Boundary". Sustainability, 2014. vol. 6, n. 11, p. 7921-7944, ISSN. 2071-1050. DOI: 10.3390/su6117921

13. LI-BAO, S., et al., "Effects of Wind Generation Uncertainty and Volatility on Power System Small Signal Stability". Journal of Electrical Engineering \& Technology, 2014. vol. 9, n. 1, p. 60-70, ISSN. 2093-7423.DOI:http://dx.doi.org/10.5370/JEET.2014.9. 1.060

14. YUE, H., Liand, G. and Zhou, M."A Probabilistic Approach to Small Signal Stability Analysis of Power Systems with Correlated Wind Sources". Journal of Electrical Engineering \& Technology, 2014. vol. 8, n. 6, p. 1605-1614,ISSN 2093-7423. DOI: http://dx.doi.org/10.5370/JEET.2013.8.6.1605

15. KUNDUR, P. "Power System Stability and Control". Ed. New York: McGraw-Hill, Inc. 1994. https://scholar.google.com.cu/scholar?q=Power+System + Stability+and+Control\&hl=es\&as_sdt=0\&as_vis $=1 \& 0$ $\mathrm{i}=$ scholart

16. MILANO F. "Power System Analysis Toolbox". PSAT Documentation Version 2.0.0 $\quad$ B. 2007. http://faraday1.ucd.ie/pnews.html 